\title{
Características físicas de grãos de feijão-fava rajada (Phaseolus lunatus L.)
}

\section{Physical characteristics of fava beans (Phaseolus lunatus L.)}

\author{
Daniel Casimiro da Silveira ${ }^{1}$, Ana Carolina Nóbrega Leite ${ }^{2}$, Newton Carlos Santos ${ }^{3}$, Josivanda Palmeira \\ Gomes $^{4}$
}

${ }^{1}$ Mestre em Sistemas Agroindustriais, Universidade Federal de Campina Grande, Pombal, Paraíba, +558399922-8451, danielcasimirodasilveira@yahoo.com.br; ${ }^{2}$ Mestre em Engenharia Química, Universidade Federal da Paraíba, João Pessoa, Paraíba, caarol.nobregaleite@gmail.com; ${ }^{3}$ Bacharel em Química Industrial, Universidade Estadual da Paraíba, Campina Grande, Paraíba, newtonquimicoindustrial@gmail.com; ${ }^{4}$ Doutora em Engenharia de Alimentos, Universidade Federal de Campina Grande, Campina Grande, Paraíba, josivanda@gmail.com

\section{A R T I G O}

Recebido: 25/07/2019

Aprovado: 19/09/2019

\section{R E S U M O}

$\mathrm{O}$ conhecimento das propriedades físicas dos produtos agrícolas apresenta um relevante papel no estudo dos processos industriais de colheita e pós-colheita, visando obter melhores condições de dimensionamento de equipamentos e armazenamento. Assim, o presente trabalho tem como objetivo avaliar os efeitos da secagem e de diferentes cultivares nas propriedades físicas dos grãos de feijão-fava rajada. Foram avaliados 4 tratamentos, nos quais as amostras de grãos in natura produzidos no estado da Paraíba e Pernambuco foram submetidas ao processo de secagem por $30 \mathrm{~h}$ a $45{ }^{\circ} \mathrm{C}$ e umidade relativa do ar de $62 \%$. Os tratamentos foram avaliados quanto aos parâmetros teor de água, atividade de água, massa individual do grão, massa específica real e aparente, ângulo de repouso dinâmico e dimensões do grão $(\mathrm{a}, \mathrm{b}, \mathrm{c})$, além de terem sido obtidos os dados de porosidade e volume do grão. Observou-se que o processo de secagem influencia as propriedades físicas do material, proporcionando um aumento das massas específicas aparente e real. Os valores de atividade de água, massa individual, volume, porosidade, ângulo de repouso dinâmico e dimensões mutuamente perpendiculares dos grãos decresceram após a redução do teor de água. A esfericidade foi influenciada de forma distinta entre os tratamentos devido ao encolhimento desuniforme nas dimensões características durante o processo de secagem.

\begin{abstract}
A B S T R A C T
The knowledge of the physical properties of agricultural products play a relevant role in the study of industrial harvesting and postharvest processes, aiming at better equipment sizing and storage conditions. Thus, the present work aims to evaluate the effects of drying and different cultivars on the physical properties of split bean beans. Four treatments were evaluated, in which samples of fresh grain produced in the state of Paraíba and Pernambuco were submitted to the drying process for $30 \mathrm{~h}$ at $45^{\circ} \mathrm{C}$ and $62 \%$ relative humidity. The treatments were evaluated for the parameters water content, water activity, individual grain mass, actual and apparent specific mass, dynamic angle of repose and grain dimensions (a, $\mathrm{b}, \mathrm{c})$. porosity and grain volume. It was observed that the drying process influences the physical properties of the material, providing an increase of apparent and actual specific masses. The values of water activity, individual mass, volume, porosity, dynamic resting angle and mutually perpendicular grain dimensions decreased after the reduction of water content. The sphericity was differently influenced between treatments due to uneven shrinkage in the characteristic dimensions during the drying process.
\end{abstract}

Os grãos verdes e secos, as vagens verdes e as folhas do feijão-fava, podem ser consumidas pelo homem; trata-se de uma das principais leguminosas cultivadas na região tropical, que apresenta potencial para o fornecimento de proteína vegetal à população e diminuição de dependência, quase exclusiva, do feijão-comum do grupo carioca (GUIMAR ÃES et al., 2007). 2016).

\section{Revista Verde}

ISSN 1981-8203

Pombal, Paraíba, Brasil v. 14, n.4, out.-dez, p.518-523, 2019

doi: 10.18378/rvads.v14i4.6811 
No Brasil, a fava é cultivada em quase todo território nacional, apresentando relativa importância econômica em alguns estados, principalmente nos da região Nordeste (MEDEIROS et al., 2015). O Nordeste é responsável por $92 \%$ da produção de feijão-fava no Brasil, com montante anual de 9.330 toneladas, com destaque aos Estados do Ceará e Paraíba, responsáveis por $79 \%$ da produção total da região, seguidos de Piauí, Pernambuco e Rio Grande do Norte (IBGE, 2017).

Similarmente ao que acontece com outras culturas, os grãos de feijão devem ser pré processados para que viabilizem uma armazenagem segura mantendo seus atributos físicos e químicos. Dos processos comumente utilizados destaca-se a secagem como sendo um dos principais, pois garante a redução do teor de água dos produtos agrícolas (ARAÚJO et al., 2018). A redução da água livre eleva a pressão osmótica de seu meio e consequentemente, a proliferação de microrganismos é contida; também nessa situação, enzimas que provocam alterações perdem sua atividade (EVANGELISTA, 2005).

A redução do teor de água dos grãos influencia diretamente na alteração das suas propriedades físicas durante a secagem. As propriedades físicas dos produtos agrícolas têm seu uso irrestrito, podendo ser utilizado em estudos de aerodinâmica, na otimização dos processos industriais, projeto e dimensionamento de equipamentos empregados nas operações de colheita e pós-colheita (RESENDE et. al., 2008). Corrêa et al. (2002) ressaltam que o conhecimento das características físicas em produtos granulares tem grande importância em estudos de transferência de calor e massa e movimentação de ar, o que reflete diretamente no armazenamento dos grãos.

Nesse contexto, considerando a importância do assunto e variabilidade existente nas propriedades físicas dos produtos agrícolas de diferentes espécies e variedades, o presente trabalho teve como objetivo determinar as propriedades físicas de grãos de feijão-fava rajada (Phaseolus lunatus L.) antes e após o processo de secagem.

\section{MATERIAL E MÉTODOS}

O experimento foi conduzido nos meses de junho e julho de 2019 no Laboratório de Armazenamento e Processamento de Produtos Agrícolas (LAPPA) da Unidade Acadêmica de Engenharia Agrícola, da Universidade Federal de Campina Grande - PB e no Laboratório de Termodinâmica do Centro de Tecnologia da Universidade Federal da Paraíba - Campus João Pessoa.

Foram utilizadas duas amostras de grãos de feijão-fava rajada frescos, obtidos no comércio popular da cidade de João Pessoa-PB e na Central Estadual de Abastecimento e Logística de Pernambuco (CEASA/PE), localizada em Recife-PE. Os produtos foram debulhados manualmente, encaminhados para o laboratório e submetidos a um processo de limpeza para remoção de impurezas e grãos quebrados ou danificados. Todos os grãos foram reunidos e posteriormente selecionados, procurando-se obter uma quantidade uniforme quanto ao tamanho e o grau de maturação, determinado pela coloração da casca.

Posteriormente, amostras foram submetidas à secagem em uma estufa com circulação forçada de ar, e mantidas nas condições de temperatura controlada do ar de secagem de 45 ${ }^{\circ} \mathrm{C}$, umidade relativa do ar de $62 \%$ e tempo de secagem de 30 h. Em seguida, todos os grãos secos foram acondicionados em sacos herméticos de polietileno.

Foram realizados 4 tratamentos: $\mathrm{T} 1=$ grãos in natura produzidos na Paraíba $(\mathrm{PB})$; T2 = grãos in natura produzidos em Pernambuco $(\mathrm{PE})$; T3 = grãos produzidos na Paraíba $(\mathrm{PB})$ secos em estufa de circulação forçada de ar por $30 \mathrm{~h}$ à $45^{\circ} \mathrm{C}$ e $\mathrm{T} 4$ = grãos produzidos em Pernambuco $(\mathrm{PE})$ secos em estufa de circulação forçada de ar por $30 \mathrm{~h}$ à $45^{\circ} \mathrm{C}$.

\section{Teor de água}

Os teores de água dos grãos de feijão-fava rajada in natura e secos foram determinados pelo método gravimétrico, utilizando-se uma estufa a uma temperatura de $105 \pm 1{ }^{\circ} \mathrm{C}$, durante 24 h e em triplicata (BRASIL, 2009).

Utilizou-se a equação 1 para determinação do teor de água em base úmida $\left(\mathrm{X}_{\mathrm{bu}}\right)$ dos grãos in natura.

$$
X_{b u}(\%)=\left(\frac{m_{\text {água }}}{m_{\text {amostra }}}\right) \times 100
$$

Para a determinação do teor de água em base seca $\left(\mathrm{X}_{\mathrm{bs}}\right)$ foi utilizada a equação 2 .

$$
X_{b s}(\%)=\left[\frac{X_{b u}}{\left(100-X_{b u}\right)}\right] x 100
$$

\section{Atividade de água $\left(a_{w}\right)$}

$A a_{w}$ foi obtida a partir de leitura direta no equipamento Novasina, modelo LabMaster®, devidamente calibrado à temperatura de $25{ }^{\circ} \mathrm{C}$ com soluções padrões, com uma precisão de $\pm 0,003$. A análise foi realizada em triplicata.

\section{Massa individual do grão ( $\mathbf{m}_{\text {grão }}$ )}

O valor da massa individual dos grãos de feijão-fava rajada foi obtido através da pesagem em balança analítica de precisão $0,001 \mathrm{~g}$, em 30 (trinta) grãos tomados ao acaso.

\section{Volume Individual}

A determinação do volume individual foi realizada através do método de deslocamento de água por pesagens. Inicialmente, foram pesados individualmente os grãos em balança analítica. Depois de pesados os grãos, pesou-se um béquer contendo água, numa quantidade suficiente para cobrir totalmente o grão. A última pesagem foi a do béquer com água + grão submerso, e para isso utilizou-se uma seringa fixada no material, acoplada a um suporte, que permitia o movimento até a completa imersão do grão, centralizado e sem que este tocasse as paredes e o fundo do béquer, causando um deslocamento de massa de fluido igual ao seu volume (ALMEIDA et al., 2006). O volume foi determinado pela equação 3 .

$$
\operatorname{Volume}\left(\mathrm{cm}^{3}\right)=\frac{\left(m_{\text {becker }}+\text { água }+ \text { grão }\right)-\left(m_{\text {becker }}+\text { água }\right)}{\rho_{\text {água }}} \quad \text { (Eq. 3) }
$$

\section{Massa específica real $\left(\partial_{\text {real }}\right)$ e massa específica aparente} $\left(\partial_{\mathrm{ap}}\right)$

O cálculo das massas específicas foi realizado conforme metodologia descrita por Almeida et al. (2006). A massa específica real foi definida de acordo com a relação entre a massa de uma unidade do grão e seu volume, determinada através da equação 4 .

$$
\partial_{\text {real }}\left(\mathrm{g} \cdot \mathrm{cm}^{-3}\right)=\frac{m}{V}
$$

A massa específica aparente foi calculada através da relação entre a massa dos grãos e um determinado volume ocupado por eles (volume do recipiente) (Equação 5). 


$$
\partial_{\text {ap }}\left(\mathrm{g} \cdot \mathrm{cm}^{-3}\right)=\frac{m}{V_{\text {becker }}}
$$

\section{Porosidade ( $\varepsilon$ )}

A porosidade foi definida como sendo a percentagem de espaços vazios existentes na massa dos grãos e sua determinação foi realizada conforme Gustafson e Hall (1972) através da equação 6 .

$$
\varepsilon(\%)=\frac{\left(\partial_{\text {real }}-\partial_{a p}\right)}{\partial_{\text {real }}}
$$

\section{Ângulo de repouso dinâmico $\left(\theta_{\text {rd }}\right)$}

O ângulo de repouso dinâmico é a inclinação da superfície plana, em que se encontram empilhados os grãos, necessária para iniciar o movimento de derramamento (escoamento) destes. O ângulo de repouso dinâmico dos grãos foi determinado usando-se uma estrutura de madeira montada sobre uma plataforma plana, porém móvel, a qual foi inclinada suavemente por um mecanismo, como mostra a Figura 1. A plataforma foi inclinada até se conseguir o início do movimento dos grãos. Naquele instante mediu-se o ângulo correspondente ao início do movimento, com o auxílio de um transferidor, obtendo-se o ângulo de repouso dinâmico (ALMEIDA et al., 2006). As determinações das amostras foram realizadas em triplicata.

Figura 1. Dispositivo para determinação do ângulo de repouso dinâmico de grãos.

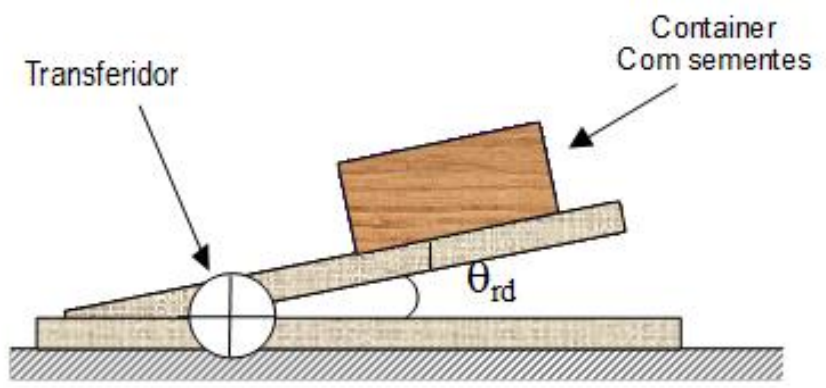

Fonte: ALMEIDA et al. (2006).

\section{Dimensões}

Os grãos de feijão-fava possuem uma forma semelhante a um elipsóide tri-axial, como a maioria dos grãos, e três medidas são necessárias: o comprimento "a", representado pelo maior diâmetro, a largura "b", representada pelo diâmetro intermediário e a espessura "c", representada pelo menor diâmetro para obtenção de tais dados, como mostra a Figura 2.

Figura 2. Figura geométrica e medidas que devem ser feitas para definir o seu tamanho.

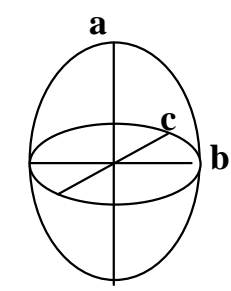

Elipsóide triaxial $a \neq b \neq c$

Fonte: ALMEIDA et al. (2006).

A determinação das dimensões mutuamente perpendiculares dos grãos foi realizada conforme metodologia de Mohsenin (1986), através do método do paquímetro digital, calibrado a $25{ }^{\circ} \mathrm{C}$ e com precisão de 0,01 , em 30 (trinta) sementes tomadas ao acaso.

\section{Esfericidade $(\varphi)$}

A forma dos grãos de feijão-fava rajada, considerados semelhantes a elipsóides, foram analisados pela esfericidade a partir das medidas das dimensões características, obtidas por paquímetro digital e considerando a equação 7 (GUPTA; DAS, 1997).

$$
\varphi(\%)=\left[\frac{(a b c)^{\frac{1}{3}}}{a}\right] x 100
$$

\section{Análise Estatística}

Os dados de massa individual, volume, massa específica real e aparente, porosidade, dimensões e esfericidade foram submetidos à análise de variância e as médias ao teste de Tukey, ao nível de $1 \%$ e $5 \%$ de probabilidade, utilizando o software ASSISTAT. A análise estatística avaliou os dados das propriedades físicas dos tratamentos T1 e T2 (in natura) em função do teor de água em base úmida (BRASIL, 2009) e dos tratamentos T3 e T4 (secos) em função do teor de água em base seca (BRASIL, 2009).

\section{RESULTADOS E DISCUSSÃO}

Os grãos de feijão-fava rajada produzidos na Paraíba e Pernambuco foram submetidos a secagem nas condições apresentadas com massas iniciais de 194,58g e 142,10g, resultando em massas finais de $79,07 \mathrm{~g}$ e $142,10 \mathrm{~g}$, respectivamente. A Tabela 1 apresenta os valores dos teores de água e atividade de água determinados nos grãos de feijãofava rajada in natura e seca produzidos na Paraíba e em Pernambuco.

Tabela 1. Teores de água e atividade de água dos grãos de feijão-fava rajada (média \pm desvio padrão).

\begin{tabular}{cccc}
\hline \multirow{2}{*}{ Amostras } & \multicolumn{2}{c}{ Teor de Água } & Atividade água \\
\cline { 2 - 4 } & $\mathrm{X}_{\mathrm{bu}}(\%)$ & $\mathrm{X}_{\mathrm{bs}}(\%)$ & $\left(\mathrm{a}_{\mathrm{w}}\right)$ \\
\hline $\mathrm{T} 1$ & $50,49 \pm 0,77$ & - & $0,995 \pm 0,000943$ \\
$\mathrm{~T} 2$ & $64,95 \pm 0,42$ & - & $0,996 \pm 0,001247$ \\
$\mathrm{~T} 3$ & $7,34 \pm 0,38$ & $7,78 \pm 0,45$ & $0,301 \pm 0,020434$ \\
$\mathrm{~T} 4$ & $6,92 \pm 0,46$ & $7,18 \pm 0,53$ & $0,299 \pm 0,026247$ \\
\hline
\end{tabular}

Médias de três repetições ( \pm desvio padrão). T1 $=$ grãos in natura produzidos na Paraíba; T2 = grãos in natura produzidos em Pernambuco; T3 = grãos produzidos na Paraíba secos em estufa de circulação forçada de ar por $30 \mathrm{~h}$ à $45^{\circ} \mathrm{C}$ e T4 = grãos produzidos em Pernambuco secos em estufa de circulação forçada de ar por $30 \mathrm{~h}$ à $45^{\circ} \mathrm{C}$.

Entre as amostras in natura, o feijão-fava produzido em Pernambuco (T2) apresentou um maior teor de água em base úmida $(64,95 \pm 0,42)$, sendo confirmado por também apresentar uma maior atividade de água $(0,996)$. Nas amostras submetidas a secagem, o feijão-fava produzido em PE (T4) apresentou um menor teor de água em base seca $(7,18)$, também apresentando uma menor atividade de água $(0,299)$, sugerindo uma melhor conservação do material.

Os grãos que passaram pelo processo de secagem perderam água com a evaporação que estava em contato direto com a estrutura celular que é conhecida como "água livre". Sendo que está "água livre" está diretamente relacionada com a deterioração e vigor dos grãos e consequentemente com a sua conservação (OLIVEIRA et al., 2014). De acordo com Oliveira et al. (2006) os grãos são materiais higroscópicos e têm a capacidade de absorver, ceder ou reter água e, dessa forma sua umidade é influenciada 
principalmente pela umidade relativa e temperatura do ar quer as rodeiam; sementes com 11 a $13 \%$ de teor de água respiram relativamente pouco, assim a baixa umidade do grão propicia uma diminuição na taxa de respiração que por sua vez reduz a deterioração.

$\mathrm{Na}$ Tabela 2 estão apresentados os valores médios de massa do grão e volume das amostras avaliadas de acordo com os respectivos tratamentos em função do teor de água. A partir da análise de variância observou-se que houve influência significativa $(\mathrm{p}<0,05)$ das propriedades físicas entre as amostras de grãos das duas localidades, in natura e secos. De acordo com Pimentel-Gomes (2009), para experimentos de culturas agrícolas, os valores de coeficientes de variação $(\mathrm{CV})$ obtidos foram considerados baixos $(<10 \%)$, indicando homogeneidade das condições experimentais.

Tabela 2. Valores de massa do grão, massa específica real, massa específica aparente, volume e porosidade dos grãos de feijão-fava rajada produzidas na Paraíba e no Pernambuco.

\begin{tabular}{cccccc}
\hline \multirow{2}{*}{ Amostras } & Massa do grão $^{*}$ & Massa Específica Real $^{\mathrm{ns}}$ & Massa Específica Aparente $^{* *}$ & Volume $^{* *}$ & Porosidade $^{\mathrm{ns}}$ \\
\cline { 2 - 6 } & $(\mathrm{g})$ & $\left(\mathrm{g} / \mathrm{cm}^{3}\right)$ & $\left(\mathrm{g} / \mathrm{cm}^{3}\right)$ & $\left(\mathrm{cm}^{3}\right)$ & $(\%)$ \\
\hline T1 & $1,329 \mathrm{~b}$ & $0,885 \mathrm{a}$ & $0,439 \mathrm{~b}$ & $1,426 \mathrm{~b}$ & $50,39 \mathrm{a}$ \\
$\mathrm{T} 2$ & $1,857 \mathrm{a}$ & $0,880 \mathrm{a}$ & $0,492 \mathrm{a}$ & $1,776 \mathrm{a}$ & $54,05 \mathrm{a}$ \\
\hline $\mathrm{CV}(\%)$ & 9,95 & 4,11 & 1,78 & 5,59 & 3,56 \\
\hline T3 & $1,014 \mathrm{a}$ & $0,959 \mathrm{~b}$ & $0,546 \mathrm{~b}$ & $1,061 \mathrm{a}$ & $43,07 \mathrm{a}$ \\
$\mathrm{T} 4$ & $0,629 \mathrm{~b}$ & $1,071 \mathrm{a}$ & $0,580 \mathrm{a}$ & $0,725 \mathrm{~b}$ & $34,11 \mathrm{~b}$ \\
\hline $\mathrm{CV}^{*}(\%)$ & 8,25 & 2,68 & 1,9 & 10,96 & 5,12 \\
\hline
\end{tabular}

$\mathrm{CV}=$ Coeficiente de variação, $\mathrm{ns}=$ não significativo, ${ }^{*}$ Significativo a $5 \%$ de probabilidade, **Significativo a $1 \%$ de probabilidade. T1 = grãos in natura produzidos na Paraíba; T2 = grãos in natura produzidos em Pernambuco; T3 = grãos produzidos na Paraíba secos em estufa de circulação forçada de ar por 30 $\mathrm{h}$ à $45^{\circ} \mathrm{C}$ e T4 = grãos produzidos em Pernambuco secos em estufa de circulação forçada de ar por $30 \mathrm{~h}$ à $45^{\circ} \mathrm{C}$.

Observa-se, a partir da Tabela 2, que a diminuição nos valores da massa unitária e volume dos grãos de feijão-fava rajada está relacionada à redução do teor de água das amostras submetidas à secagem, provavelmente devido ao efeito combinado entre a deformação do grão e a presença de espaços vazios no seu interior, ao mesmo tempo em que ocorre redução da massa, provocando uma contração ou diminuição do volume do material.

Analisando as massas específicas real e aparente dos grãos de feijão-fava rajada nos diferentes tratamentos, ambas relacionadas a massa do produto e o volume que ela ocupa, verificou-se que os grãos in natura apresentaram menores massas específicas que os grãos submetidos ao tratamento térmico. Os valores experimentais da massa específica aparente e real para o material estudado variaram entre entre 0,49 a 0,58 g.cm ${ }^{-3}$ e 0,88 a 1,07 g.cm ${ }^{-3}$, respectivamente, para o teor de água do produto variando de 64,95 a 6,92\% (b.u.). Estes resultados são coerentes com alguns dos produtos agrícolas pesquisados como: feijão de cultivares Valente e Pontal (Jesus et al., 2013), feijão fradinho (Lanaro et al., 2011), grãos de girassol (Rodrigues et al, 2018), grão de bico (Konak et. al, 2002) e lentilha (Amin et al., 2004).

A secagem dos grãos de feijão-fava rajada proporcionou uma diminuição na porosidade dos mesmos, apresentando valores entre 34,11 a 43,07\%, para a faixa de teor de água de 7,18 a 7,78\% (b.s.). Logo, evidencia-se que a redução do teor de água no produto tem influência direta sobre a sua porosidade intergranular. Segundo Rodrigues et al. (2018), a formação de espaços vazios é favorecida quando o grão apresenta elevado teor de água, podendo ter contribuição para essa tendência de redução da porosidade após a secagem.

Diversos pesquisadores observaram comportamentos semelhantes ao do feijão-fava rajada neste presente estudo, entre eles: Ribeiro et al. (2005), estudando grãos de soja durante o processo de secagem, observaram que a redução do teor de água provoca a diminuição linear da porosidade, variando de 41,1 a 44,7\% para uma faixa de teor de água entre 15 a $31 \%$ (b.s.), além de um aumento das massas específicas aparente e real; Resende et al. (2008), que estudaram a influência da redução do teor de água sobre as propriedades físicas dos grãos de feijão da cultivar Vermelho Coimbra, observaram uma diminuição da porosidade e o aumento das massas específicas aparente e da massa específica unitária; Sousa et al. (2016), estudando grãos de arroz vermelho, observaram um aumento proporcional da porosidade, variando de 46,77 a $51,74 \%$, para uma faixa de teor de água entre 9,52 a 28,07 (b.u.), com o aumento do teor de água.

Quanto a comparação dos grãos produzidos nos estados da Paraíba e Pernambuco, Oliveira et. al (2014) evidenciam que o tamanho e a formas dos grãos são características genéticas, porém podem ser influenciadas pelas condições ambientais durante e posteriormente a formação dos mesmos. O conhecimento do tamanho e a formas dos grãos para cada espécie é importante para construção de equipamentos de beneficiamento de sementes, assim como a porosidade possui influência direta no dimensionamento de ventiladores do sistema de secagem de grãos. Na Tabela 3, podemos observar os valores médios dos ângulos de repouso das amostras em estudo.

Tabela 3. Ângulos de repouso dinâmicos dos grãos de feijãofava rajada.

\begin{tabular}{cc}
\hline \multirow{2}{*}{ Amostra } & Ângulo de repouso dinâmico \\
\cline { 2 - 2 } & $\Theta_{\mathrm{rd}}$ \\
\hline T1 & $32,33 \pm 0,47$ \\
T2 & $40,67 \pm 1,89$ \\
T3 & $28,33 \pm 1,25$ \\
T4 & $27,67 \pm 0,47$ \\
\hline
\end{tabular}

Médias de três repetições ( \pm desvio padrão). T1 $=$ grãos in natura produzidos na Paraíba; T2 = grãos in natura produzidos em Pernambuco; T3 = grãos produzidos na Paraíba secos em estufa de circulação forçada de ar por $30 \mathrm{~h} \mathrm{à}$ $45^{\circ} \mathrm{C}$ e T4 = grãos produzidos em Pernambuco secos em estufa de circulação forçada de ar por $30 \mathrm{~h}$ à $45^{\circ} \mathrm{C}$.

Na Tabela 3, podemos observar os valores médios dos ângulos de repouso das amostras em estudo. O ângulo de repouso dos grãos de o feijão-fava rajada variou entre 27,67 e 
$40,67^{\circ}$ de acordo com as amostras avaliadas, sendo que as amostras in natura obtiveram maiores ângulos (32, e 40,67) de repouso e os grãos secos os menores ângulos de repouso (27,67 e 28,33), confirmando estudos realizados com outros grãos que têm revelado um maior ângulo de repouso dinâmico para um maior teor de água do material (COSTA et al., 2010) e que os menores ângulos de inclinação ocorrem em grãos esféricos, grandes, lisos, sadios, íntegros, limpos e secos (ELIAS, 2008).

Na Tabela 4 estão apresentados os valores das dimensões mutuamente perpendiculares dos grãos avaliado em comprimento (a), largura (b) e espessura (c), correspondendo às medidas em milímetros, e a esfericidade. A partir da análise de variância observou-se que houve influência significativa $(\mathrm{p}<0,05)$ das dimensões $(a, b$ e c) apenas para as amostras de grãos secos, enquanto a esfericidade não foi significativa para nenhum dos tratamentos. Verificou-se ainda que os valores de coeficientes de variação obtidos foram muito baixos $(<5 \%)$, indicando homogeneidade dos dados.

Tabela 4. Dimensões dos eixos perpendiculares esfericidade dos grãos de feijão-fava rajada.

\begin{tabular}{ccccc}
\hline \multirow{2}{*}{ Amostra } & \multicolumn{3}{c}{ Dimensões $(\mathrm{mm})$} & $\begin{array}{c}\text { Esfericidade } \\
(\%)^{\mathrm{ns}}\end{array}$ \\
\cline { 2 - 4 } & $\mathrm{a}^{\mathrm{ns}}$ & $\mathrm{b}^{\mathrm{ns}}$ & $\mathrm{c}^{\mathrm{ns}}$ & $51,85 \mathrm{a}$ \\
$\mathrm{T} 1$ & $25,21 \mathrm{a}$ & $17,33 \mathrm{a}$ & $5,17 \mathrm{a}$ & $5,10 \mathrm{a}$ \\
$\mathrm{T} 2$ & $26,62 \mathrm{a}$ & $18,31 \mathrm{a}$ & $6,10 \mathrm{a}$ & 54,167 \\
\hline $\mathrm{CV}(\%)$ & 3,91 & 2,28 & 2,67 & 2,2 \\
\hline $\mathrm{T} 3$ & $24,32 \mathrm{a}$ & $16,42 \mathrm{a}$ & $5,40 \mathrm{a}$ & $52,99 \mathrm{a}$ \\
$\mathrm{T} 4$ & $21,38 \mathrm{~b}$ & $14,59 \mathrm{~b}$ & $4,52 \mathrm{~b}$ & $52,16 \mathrm{a}$ \\
\hline $\mathrm{CV}^{*}(\%)$ & 2,59 & 3,1 & 5,02 & 1,63
\end{tabular}

$\mathrm{CV}=$ Coeficiente de variação, $\mathrm{ns}=$ não significativo, ${ }^{*}$ Significativo a $5 \%$ de probabilidade, $* *$ Significativo a $1 \%$ de probabilidade. $\mathrm{T} 1=$ grãos in natura produzidos na Paraíba; T2 = grãos in natura produzidos em Pernambuco; T3 = grãos produzidos na Paraíba secos em estufa de circulação forçada de ar por $30 \mathrm{~h}$ à $45^{\circ} \mathrm{C}$ e T4 = grãos produzidos em Pernambuco secos em estufa de circulação forçada de ar por $30 \mathrm{~h}$ à $45^{\circ} \mathrm{C}$.

Observa-se que os grãos de feijão-fava in natura produzidos em Pernambuco (T2) apresentaram maiores dimensões em relação aos da Paraíba (T1), mas após passarem pelo processo de secagem sofreram uma maior redução no tamanho, comprovando os valores de umidade e atividade de água anteriormente analisados. Como pode ser observado, a secagem interferiu nos valores das dimensões dos eixos perpendiculares dos grãos de feijão-fava rajada produzidos nos diferentes tratamentos, com contrações máximas de $5,24 \mathrm{~mm}$ e $3,74 \mathrm{~mm}$, no maior eixo e no eixo central, respectivamente, da amostra in natura proveniente de PE (T2) após ser submetida à secagem (T4).

Como a maioria dos produtos agrícolas (ARAÚJO et al., 2014), os grãos apresentaram um encolhimento ligeiramente desuniforme em suas dimensões características durante o processo de secagem, apresentando maior e mais significativa diferença nas dimensões mutuamente perpendiculares entre os grãos após a redução do teor de água. Logo, evidencia-se que, assim como entre os tratamentos in natura e secos, há variação entre os grãos de diferentes cultivares e, portanto, os equipamentos de beneficiamento e armazenagem devem ser dimensionados de maneira distinta.

Também é possível verificar que a característica de esfericidade foi influenciada pelo teor de água de forma divergente entre as amostras estudadas. Enquanto a esfericidade dos grãos de feijão-fava produzidos na PB (T1) aumentaram após a secagem (T3), aqueles produzidos em PE (T2) apresentaram uma diminuição da esfericidade após o tratamento térmico (T4). Tal observação pode ser explicada pelo fato de que a redução no teor de água da amostra proveniente de PE provocou um aumento na espessura, devido a uma grande contração de comprimento e largura do material, alterando assim o seu formato. Segundo Araújo et al. (2014), valores de esfericidade abaixo de $80 \%$ evidenciam a incapacidade de classificação do material como esféricos independente do teor de água que apresentam.

De acordo com Saath et al. (2014), que estudaram a variação das características biométricas dos grãos de milho de diferentes cultivares, embora o fator genético tenha maior impacto, vários outros fatores podem interferir nas dimensões e no peso específico dos grãos, entre eles: época de plantio, incidência de luz solar ou sombreamento excessivo na época de floração, temperatura, espaçamento entre plantas, déficit hídrico, deficiência mineral do solo e época de colheita. Os fatores transporte, secagem e armazenagem também têm efeito nos valores da massa específica, principalmente se conduzidos de forma inadequada.

\section{CONCLUSÕES}

A redução do teor de água apresenta influência sobre as propriedades físicas dos grãos de feijão-fava rajada, proporcionando o aumento da massa específica aparente e da massa específica real e a diminuição da massa individual, volume, porosidade, ângulo de repouso dinâmico e dimensões mutuamente perpendiculares dos grãos. A esfericidade é influenciada pelo teor de água de forma distinta entre cultivares devido ao encolhimento desuniforme nas dimensões características durante o processo de secagem.

\section{REFERÊNCIAS}

ALMEIDA, F. de A. C.; DUARTE, M. E. M.; CAVALCANTI-MATA, M. E. R. M. Tecnologia de Armazenagem em Sementes. 1. ed. Campina Grande: Marconi, 2006. v. 1. 382p.

AMIN, M. N.; HOSSAIN, M. A.; ROY, K. C. Effect of moisture content on some physical properties of lentil seeds. Journal of Food Engineering, v. 65, p. 83-87, 2004.

ARAÚJO, W. D.; GONELI, A. L. D.; SOUZA, C. M. A.; GONÇALVEZ, A. A.; VILHASANTI, H. C. B. Propriedades físicas dos grãos de amendoim durante a secagem. Revista Brasileira de Engenharia Agrícola e Ambiental, v. 18, n. 3, p. 279-286, 2014, 10.1590/S1415-43662014000300006.

ARAÚJO, M. J. I.; BOTELHO, F. M.; BOTELHO, S. C. C.; MENEZES JÚNIOR, J. A. N.; ALMEIDA, L. C. B. Propriedades Físicas de grãos de Feijão Caupi. Congresso Brasileiro de Engenharia Agrícola, 2018.

BRASIL. Ministério da Agricultura e Reforma Agrária. Secretaria Nacional de Defesa Agropecuária. Regras para análises de sementes. Brasília, 2009. 399 p. 
CORRÊA, P. C.; AFONSO JÚNIOR, P. C.; QUEIROZ, D. M.; SAMPAIO, C. P.; CARDOSO, J. B. Variação das dimensões características e da forma dos frutos de café durante o processo de secagem. Revista Brasileira de Engenharia Agrícola e Ambiental, Campina Grande, v.6, n. 3, p. 466-470, 2002.

COSTA, A. R. da; FARONI, L. R. D'A.; ALENCAR, E. R. DE; CARVALHO, M. C. S.; FERREIRA, L. G. Qualidade de grãos de milho armazenados em silos bolsa. Revista Ciência Agronômica, v. 41, n. 2, p. 200-207, 2010.

ELIAS, M. C. Manejo tecnológico da secagem e do armazenamento de grãos. 1. ed. Pelotas: Editora Cópias Santa Cruz, 2008. v. 1. 368p.

EVANGELISTA, J. Tecnologia de alimentos; $2^{\mathrm{a}}$ Ed. São Paulo, Rio de Janeiro, Ribeirão Preto, Belo Horizonte, 2005. $652 \mathrm{p}$.

GOMES, R. S. S.; NUNES, M. C.; NASCIMENTO, L. C.; SOUZA, J. O.; PORCINO, M. M. Eficiência de óleos essenciais na qualidade sanitária e fisiológica em sementes de feijão-fava (Phaseolus lunatus L.). Revista Brasileira de Plantas Medicinais, v. 18, n. 1, p. 279-287, 2016.

GUIMARÃES, W. N. R.; MARTINS, L. S. S.; SILVA, E. F.; FERRAZ, G. M. G.; OLIVEIRA, F. J. Caracterização morfológica e molecular de acessos de feijão-fava (Phaseolus lunatus L.). Revista Brasileira de Engenharia Agrícola e Ambiental, v.11, n.1, 2007,

GUPTA, R. K., DAS, S. K. Physical properties of sunflower seeds. Journal of Agricultural Engineering Research, v. 66, n. 1, p. 1-8, 1997.

GUSTAFSON, R.J.; HALL, G.E. Density and porosity changes of shelled corn during drying. Transactions of the ASAE, St. Joseph, v. 15, n. 1, p. 523-525, 1972.

IBGE. Instituto Brasileiro de Geografia e Estatística. Produção Agrícola Municipal: Área plantada, área colhida, quantidade produzida, rendimento médio e valor da produção das lavouras temporárias. Disponível em: <https://sidra.ibge.gov.br $>$ Acesso em: Maio de 2019.

JESUS, F. F. De; SOUZA, T. G. De; TEIXEIRA, G. C. Da S.; TEIXEIRA, I. R.; DEVILLA, I. A. Propriedades Físicas de Sementes de Feijão em Função dos Teores de Água. Revista Engenharia da Agricultura, v. 21, n. 1, 2013.

KONAK, M.; ÇARMAN, K.; AYDIN, C. Physical properties of chick pea seeds. Biosystems Engineering, v. 82, n. 1, p. 73 78, 2002.

LANARO, N. Di; BAJAY, L. G.; QUEIROZ, V. M. P. De; PINTO, R. C. S.; LEITÃO, I. G. De A.; LESSIO, B. D.; AUGUSTO, P. E. D. Determinação de propriedades físicas do feijão fradinho. Revista Brasileira de Produtos Agroindustriais, v. 13, n. 1, p. 27-35, 2011.

MEDEIROS, V. S. S.; ALMEIDA, L. S.; PAULA, A. C. de; MARINI, F. S.; ARRIEL, N. H. C. Caracterização morfoagronômica de fava (Phaseolus lunatus L). Cadernos de Agroecologia, v. 10, n. 3, 2015.

MOHSENIN, N. N. Physical properties of plant and animal materials. New York: Gordon and Breach science publishers Inc., 1986. 734p.

OLIVEIRA, J. A.; GUIMARÃES, R. M.; ROSA, S. D. V. F. Processamento de sementes pós-colheita. Informe Agropecuário. Belo Horizonte, v.27, n.232, p.52-58, 2006.

OLIVEIRA, L. C.; COSTA, E.; CARDOSO, E. D.; BINOTTI, F, F. S.; JORGE, M. H. Propriedades físicas de sementes de baru em função da secagem. Revista de Agricultura Neotropical, v. 1, n. 1, p. 92-96, 2014.

PIMENTEL-GOMES, F. Curso de estatística experimental. 15. ed., Piracicaba: Fealq, 2009, 451 p.

RESENDE, O.; CORRÊA, P. C.; GONELI, A. L. D.; CECON, P. R. Forma, tamanho e contração volumétrica do feijão (Phaseolus vulgaris L.) durante a secagem. Revista Brasileira de Produtos Agroindustriais, v. 7, n. 1, p. 15-24, 2005.

RESENDE, O.; CORRÊA, P. C.; GONELI, A. L. D.; RIBEIRO, D. M. Propriedades físicas do feijão durante a secagem: Determinação e modelagem. Ciência e Agrotecnologia, v. 32, n. 1, p. 225-230, 2008.

RODRIGUES, L. M. S.; SANTOS, N. C.; FERREIRA, J. S.; SILVA, S. N.; GOMES, J. P. Influência do tempo de secagem nas propriedades físicas de grãos de girassol. Congresso Técnico Científico da Engenharia e da Agronomia, Maceió, 2018.

SAATH, R.; PEREIRA, J. T. S.; RODRIGUEIRO, G. R. O.; TONON, K. C.; LIMONI, L. H. Biometria em grãos de diferentes cultivares de milho em função do teor de água. XLIII Congresso Brasileiro de Engenharia Agrícola, Campo Grande, 2014.

SOUSA, R. V.; MATA, M. E. R. M. C.; DUARTE, M. E. M.; ALMEIDA, R. D.; ROSA, M. E. C.; SOUSA, A. C. Influência do teor de água nas propriedades físicas dos grãos de arroz vermelho em casca. Revista Brasileira de Produtos Agroindustriais, v. 18, n. especial, p. 495-502, 2016. 